\title{
POLITITIKK
}

SKANDINAVISK TIDSSKRIFT

FOR INTERNASIONALE STUDIER

Årgang 79, Nummer 1, side 1-7, 2021, ISSN 1891-1757, www.tidsskriftet-ip.no, Publisert januar 2021

FOKUS: HVA NÅ, USA?

\section{Introduksjonsessay til fokusnummer: Hva nå, USA?}

\author{
Hilde Restad (gjesteredaktør) \\ Bjørknes Høyskole, Norge
}

Den 20. januar 2021 ble fire utfordrende år med en illiberal og antidemokratisk amerikansk president avsluttet. President Joseph R. Bidens tiltredelse betyr starten på sårt tiltrengt distanse til Trump-æraen, og muligheten til å spørre: Hvor gikk USA under Trump, og hvor skal USA under Biden? De av oss som forsker på amerikansk utenrikspolitikk har særlig vært opptatt av hvordan Trump passer inn i serien presidenter siden andre verdenskrig. Trump brøt relativt klart med mye av den tverrpolitiske utenrikspolitiske konsensusen som hadde rådet i Washington, D.C. siden 1945 (Restad, 2019). Men var dette ene og alene Trumps fortjeneste - eller skyld? Og kan Biden lappe sammen et nytt utenrikspolitisk konsensus post-Trump?

Trumps fire år kan forstås som en reaksjon mot et USA i en nedadgående spiral, men han er ikke idiosynkratisk. Fenomenet Trump kan sees på som en fortsettelse av den opprinnelige reaksjonen mot den overtente og til slutt feilslåtte utenrikspolitiske storstrategien på 1990- og 2000-tallet: valget av Barack Obama i 2008. I et valgår uvanlig preget av utenrikspolitikk vant Obama først den demokratiske nominasjonen og deretter presidentvalget, blant annet på en klar avvisning av det hittil dominante utenrikspolitiske paradigmet der USA skulle ta ansvar for alt som skjedde i verden og ikke minst bruke militærmakt for å løse hva nå enn utfordringen var. Obama avviste «dumme kriger» - hans beskrivelse av Irak-krigen i 2002 som delstatssenator i Illinois. Som president stilte Obama spørsmål ved gamle antakelser og satte i gang med en relativt ambisiøs omkalibrering av amerikansk storstrategi. Obama forsøkte seg på det man hadde forventet av George H.W. Bush og Bill Clinton etter at Sovjetunionen kollapset: en re-evaluering av ens antakelser om verden og utforming av ny

\footnotetext{
^Kontaktinformasjon: Hilde Restad, e-post: Hilde.Restad@bhioslo.no

(C)2021 Hilde Restad. This is an Open Access article distributed under the terms of the Creative Commons Attribution 4.0 International License (http://creativecommons.org/licenses/by/4.0/), allowing third parties to copy and redistribute the material in any medium or format and to remix, transform, and build upon the material for any purpose, even commercially, provided the original work is properly cited and states its license.

Citation: Restad, H. (2021). Introduksjonsessay til fokusnummer: Hva nå, USA? Internasjonal Politikk, 79(1), 1-7. http://dx.doi.org/10.23865/intpol.v79.2759
} 


\section{Hilde Restad}

storstrategi. Dette var et initiativ på overtid etter USAs manglende evne (og vilje) til å justere kurs etter at den kalde krigen var over (Chollet \& Goldgeier, 2008).

Obama forsøkte til dels forgjeves å nedjustere USAs tilstedeværelse i Midtøsten og Sentral-Asia slik at USA kunne vende blikket mot den kommende motstanderen Kina (Goldberg, 2016). Samtidig videreførte han mye av krigen mot terror som redefinert i Bush-administrasjonens andre periode (Restad, 2012). Obamas delvis grunnleggende, delvis overflatiske kursendring ble gjenstand for mye debatt og (overfor-)tolkning: var Obama en realist, som hadde gitt opp USAs misjon som verdens frelser? Republikanerne kritiserte jo Obama for ikke å tro på amerikansk eksepsjonalisme, hvis implikasjon var at han var totalt uegnet til å være «the leader of the free world» (som amerikanerne noe pinlig fortsatt kaller det) (Restad, 2014, s. 1-2).

I dette spesialnummeret kan dere lese Johannes Røs analyse av Obama og Trump. Som han skriver vil mange stusse over sammenligningen av Obama og Trump «ettersom deres diplomatiske opptreden, retoriske stil og ikke minst analytiske refleksjonsnivå representerer to ytterligheter. Men nettopp fordi kontrasten til Trump er så påfallende, er det lett å overse at egennyttig tenkning hadde stort gjennomslag hos Obama.» Røs hovedspørsmål er: Kan vi kanskje forstå Obama og Trump som to realister etter en lang rekke idealister? Gitt Norges relativt beskjedne antall forskere som fokuserer på amerikansk utenrikspolitikk er jeg glad for at Rø og jeg er relativt uenige. Røs vinkling bygger i hovedsak på realpolitisk analyse, mens min forskning baserer seg på konstruktivismeteorien innenfor IR. Konstruktivister antar at ideer og interesser ikke kan forstås som en dikotomi, men heller at ideer og identiteter former våre interesser. Således er Røs artikkel, ikke minst hans konklusjon om at idealpolitikk kan være realpolitikk, starten på en spennende debatt som vil ta oss inn i Biden-administrasjonens æra: hvordan definerer Biden USAs «nasjonale interesser»? Min tese er at Bidens oppfattelse av USA som en eksepsjonell nasjon vil forme hvordan han definerer USAs «nasjonale interesser», slik vi har sett med mange tidligere presidenter (Restad, 2014, 2019). Biden-administrasjonen blir således en test av Røs argument, i og med at han peker på strukturelle årsaker til at man nå har sett to «realister» som presidenter. Jeg er takknemlig for Røs bidrag, som evner å røske opp i etablerte antakelser og få oss til å tenke mer helhetlig om post-krigen mot terror æraen i amerikansk utenrikspolitikk.

En av disse etablerte antakelsene er at Trumps "America First»-agenda representerte såkalt isolasjonisme. Mange av hans velgere oppfattet ham som en som kom til å tilbaketrekke amerikanske styrker fra ulike kriger og intervensjoner, ikke igangsette nye militære gjøremål utenlands og heller fokusere på innenrikspolitikk. Dette var forståelig, siden Trump valgte mottoet «America First» for å oppsummere sin utenrikspolitiske agenda, et motto med spesifikke historiske konnotasjoner (Leffler, 2018). Dette viste seg å ikke være riktig (McDonald \& Parent, 2019). I dette spesialnummeret kan vi lese Bjørn Olav Knutsen og Kari Tvetbråtens artikkel om Trump-administrasjonens tilnærming til EUs sikkerhetssamarbeid. Deres analyse av Trump-administrasjonens National Security Strategy (2017) viser at USA under 
Trump ikke hadde noen planer om å trekke seg tilbake fra verden og «isolere» seg. I NSS (2017) finner vi derimot «en målsetting om å opprettholde et amerikansk sikkerhetspolitisk lederskap».

Hadde isolasjonisme vært en sann amerikansk utenrikspolitisk tradisjon, var det slutten på den kalde krigen som var den naturlige tiden å gjeninnføre denne. Den historiske seieren over Sovjetunionen etterlot en fiendeløs verden som muliggjorde om ikke tilbaketrekning fra den internasjonale arenaen så i alle fall en grundig reevaluering av akkurat hvor mye tilstedeværelse og militærbudsjett som faktisk var nødvendig nå som USA var verdens unipol (Restad, 2014, s. 197-200). Heller enn å justere ned ambisjonene for egen utenrikspolitikk, gikk dog USA inn i 1990-tallet med en oppgradert versjon av amerikansk eksepsjonalisme på bensintanken. Politikere i begge partier opererte med en Francis Fukuyama-inspirert tolkning av slutten på den kalde krigen som USAs seier over verdenshistorien.

Det var denne forestillingen om USA som svaret på verdens spørsmål som rammet inn Bush-administrasjonens «krig mot terror». Heller ikke et historisk angrep på amerikansk jord førte til en reevaluering av hvordan, hvor mye og hvorfor USA skulle engasjere seg internasjonalt. Det var det ingen grunn til, ifølge Bushadministrasjonen, som argumenterte for at USA hadde blitt angrepet på grunn av sine «freedoms» (Bush, 2001a) og at USA nå måtte bekjempe «evil-doers» og terrorisme med enorm militær makt (Bush, 2001b). En sterk tro på USAs eksepsjonelle rolle i verdenshistorien, koplet med USAs ubestridte posisjon som unipol, førte til en i etterkrigssammenheng historisk unilateral storstrategi som møtte sterk motstand fra sågar allierte som fiender. Denne unilaterale tilnærmingen ble da også nedjustert i Bush-administrasjonens andre periode. Krigen mot terror var i stor grad mislykket, men vanskelig å avslutte. Igjen stod et USA i økonomisk krise, som ikke helt visste hva det ville eller om det burde.

Samtidig som USA dro utenlands for å bekjempe monstre (som John Quincy Adams en gang advarte mot), og med dette økte både sitt militærbudsjett og det føderale byråkrati i form av det nye Homeland Security-departementet, var USA innad i økende grad karakterisert av økt økonomisk ulikhet, økt politisk polarisering, økt mangfold og ikke minst en radikalisering av deler av det republikanske partiet. Denne radikaliseringen var til dels rettet mot sin egen partielite, en utvikling Trump senere bygget videre på og dro fortjeneste av (Williamson, 2016). Knutsen og Tvetbråtens artikkel klargjør det som burde vært åpenbart for mange hele veien: Trump var aldri noen isolasjonist, men videreførte heller Bushs unilaterale, militaristiske tilnærming til internasjonal konflikt - dog uten det ideologiske eksepsjonalistiske rammeverket. Når de skriver at «amerikansk uttreden av Paris-avtalen, tilbaketrekningen fra atomavtalen med Iran, utmeldelsen fra Verdens helseorganisasjon (WHO) og varselet om at USA trekker 9500 soldater fra Tyskland uten konsultasjoner med europeiske allierte, [har] vist amerikansk unilateralisme i praksis» får man assosiasjoner til de tidlige analysene av Bush-administrasjonen, hvis første år i stor grad bestod av å trekke seg ut av ting. 


\section{Hilde Restad}

Trump-æraen innebærer fortsettelsen av USAs mer ambivalente holdning til sin egen rolle post-Bush. Dette «betyr en til dels betydelig mindre støtte til multilaterale løsninger på regionale og globale spørsmål» skriver Knutsen og Tvetbråten. Trump-administrasjonenes unilaterale tilnærming kan sees som en klar fortsettelse av Bush-administrasjonens samme holdning til "sitt eget" internasjonale system. Dette betyr, som forfatterne helt riktig påpeker, «at det tradisjonelle grunnlaget for det transatlantiske sikkerhetsfellesskapet endres» og at lederskapskonflikten ikke vil forsvinne med Biden «siden dette grunnleggende sett dreier seg om de maktpolitiske forholdene mellom USA og EU-prosessens videre utvikling».

Utfordringen til de av oss som forsøker å si noe om Trump-administrasjonens utenrikspolitikk er at det åpenbart var ulike aktører med ulike interesser som snakket for «USA» mens Trump var president. Det er usikkert hvorvidt Trump i det hele tatt leste sin egen NSS. Det virker klart at der hans første forsvarsminister James Mattis ønsket å bygge videre på transatlantisk sikkerhetssamarbeid, var det usikkert i hvilken grad hans sjef ønsket dette. Dette var ikke en triviell uenighet som handlet om ord versus handlinger eller detaljer versus visjoner, og da «nytter det heller ikke [...] å vise til at USA tross alt har styrket sin militære tilstedeværelse i Europa de seneste årene» skriver Knutsen og Tvetbråten. «Her har argumentene vært at handlinger teller mer enn ord og holdninger. Så lenge disse militære enhetene i mindre grad ikke er knyttet til en kollektivisert europeisk sikkerhetsordning, vil ikke økt militær tilstedeværelse nødvendigvis bidra nevneverdig til europeisk sikkerhet» skriver Knutsen og Tvetbråten.

Trumps fire år representerte ikke bare en usikker tid for det transatlantiske samarbeidet og europeisk sikkerhetssamarbeid, som Knutsen og Tvetbråten viser, men satte det endelige punktum for en æra i amerikansk utenrikspolitikk der allierte visste at USA var forpliktet til å lede det systemet det hadde satt opp i 1945 (om i noen perioder mer unilateralt enn multilateralt). Et nytt samarbeid må bygges på felles verdier og interesser. Men det kan ikke bygges et sterkt transatlantisk samarbeid for en post-kald krig og post-krig mot terror æra dersom USA og de viktigeste europeiske statene som Frankrike, Tyskland og Storbritannia er uenige om hvilken vestlig identitet som legger det normative grunnlaget for forpliktelsen. Vi må vite hvem vi er og hva vi står for, før vi kan vite hva vi vil.

At det bare skulle fire år med en uvanlig president til for å svekke det vestlige samarbeidet så grundig viser hvor viktig individuelle USAs presidenter er i utformingen av USAs utenrikspolitikk og derigjennom internasjonal politikk. Likevel er det gjerne slik at amerikanske presidentkandidater stiller $i k k e$ fordi de er interesserte i, eller har noen erfaring med, utenrikspolitikk, men fordi de er opptatt av innenrikspolitikk. Dette beskrev Woodrow Wilson godt da han rett før sin innsettelse i 1913 uttalte at "It would be the irony of fate if my administration had to deal chiefly with foreign affairs» (Brands, 2004, s. 503). Den siste artikkelen i vårt spesialnummer tar for seg fenomenet "valgbarhet» ("electability»). Vårin Alme analyserer innsiktsfullt begrepet som til dels dominerte demokratenes nominasjonsvalg i 2019-2020. Heller enn hvem som ville være den beste presidenten, om det nå skulle gjelde innenriks- eller 
utenrikspolitikk, var demokratiske nominasjonsvelgere oppslukt i en ting: hvilken kandidat som andre ville stemme på, altså den mest «valgbare» kandidaten. Dette fordi det overordnede målet i 2020 var å beseire Donald Trump, og så fikk ens ulike politiske hjertesaker vente til neste nominasjonsrunde.

Dette kan forstås på ulike måter. En måte er å berømme demokratene for i møte med en trussel mot eget demokrati å endelig motbevise tesen formulert av Bill Clinton om at "Democrats want to fall in love, Republicans just fall in line». Altså at der republikanerne er flinke til å tenke strategisk og holde linja, så må demokratene alltid følge hjertet sitt - noe som gjerne fører til kaos og uro i indre rekker. 2020 var et klart unntak fra dette, da demokratene var uvanlig samkjørte og relativt raskt klarte å samle seg bak den kandidaten de mente var mest «valgbar» - i sterk kontrast til 2016. Alme argumenterer for at vi i 2020 så en ekstrem variant av strategisk stemmegiving basert på velgeres egne evalueringer av hva som var «valgbart», et fenomen hun kaller «valgbarisme». Dette fenomenet er det nødvendig å advare mot, mener hun. Demokratiske nominasjonsvelgere var så fokusert på å slå Trump at de i mye større grad enn tidligere år utslettet egne politiske preferanser både når det gjaldt saker, men også tanker om representasjon og identitet, og stemte på den garantert mest «valgbare» kandidaten. Men hva betyr det å være valgbar? I 2020 betød det å være en hvit, eldre mann med relativt moderate holdninger. Å være en kvinnelig kandidat i 2020 ser ut til å ha vært negativt, fordi mange nok demokratiske nominasjonsvelgere etter Clintons tap i 2016 antok at selv om de var klare for en kvinnelig kandidat, var det ingen andre som var det (NBC, 2020).

Biden beviste sin valgbarhet ved å vinne valget. Hans inntreden i Det hvite hus skjer på et ekstremt sårbart tidspunkt i amerikansk og internasjonal historie. USAs relative makt er nedadgående - en trend som har akselerert under Trump. USAs innenrikspolitiske tilstand er skjør - en trend som har akselerert under Trump. USA er svekket av sterk polarisering, et radikalt republikansk parti og en totalt feilslått pandemirespons. Biden vil i motsetning til sin forgjenger forsøke å samle USA og bekjempe virkelige - heller enn imaginære - fiender. Han vil forsøke å bygge opp, heller enn å rive ned. Men det kanskje viktigste byggverket Biden må jobbe med, er en felles amerikansk identitet. Hvilket land skal USA være, for seg selv og for verden? Økende mangfold betyr at der kun er en mulig løsning på USAs identitetskrise: en nasjonal identitet og et felles formål om å stå for tolerante verdier, ikke hudfarge og religion - statsborgerlig nasjonalisme heller enn etnisk nasjonalisme (Restad, 2020). USA skal nok en gang forsøke å leve opp til de idealene landet ble grunnlagt på. Dette ble reflektert i Bidens valgmotto «kampen for landets sjel» («battle for the soul of our nation»). Hans kampanje handlet om å subtilt kategorisere Trump som anti-amerikansk, som en som ikke representerte amerikanske verdier som mangfold, toleranse og pragmatisk politisk samarbeid. Bidens noe gammeldagse, nær naive tiltro til sitt eget land ble godt oppsummert av hans tilsynelatende spontane utbrudd, "For Lord's sake, this is the United States of America!» ("Herregud, dette er jo USA!») i hans takketale da han mottok nominasjonen 20. august 2020. Biden har klart å opprettholde en genuint sjokkert tilstand over at Trump ble valgt og over alt som har 
skjedd de siste fire årene. Han personifiserer på mange måter den delen av USA og resten av verden som har stirret i konstant skrekk på sirkuset i Det hvite hus.

Europeiske allierte, som Norge, puster nok lettet ut over at Biden vant valget. En god nyhet for de av oss som er opptatt av det transatlantiske sikkerhetssamarbeidet er at Trumps fire år har endret amerikaneres syn på internasjonalt samarbeid og USAs rolle i verden i en mer positiv retning (Monten et al., 2020). Trump klarte faktisk ikke å minske amerikaneres støtte til internasjonal handel, innvandring eller militære allianser. Det er håp for tverrpolitisk samarbeid på en rekke utenrikspolitiske utfordringer, som Kina, handel, cybersikkerhet og global helse / pandemisikkerhet. Der det derimot er ventet stor motstand fra republikanerne i kongressen, er på klima. Her må nok Biden lene seg på presidentens makt til å utstede presidentordre ("executive orders»), noe som er sårbart for umiddelbar reversering av neste president.

Men kanskje blir pausen fra USAs kaos for kort. Selv om fire år med Trump har gjort amerikanere generelt sett mer vennligstilte overfor internasjonalt samarbeid, så er det stor uenighet mellom demokrater og republikanere (Balz \& Clement, 2020). Dermed er det ikke noe ny tverrpolitisk utenrikspolitisk konsensus å spore i nær amerikansk fremtid. Så lenge Trump - eller en annen etnonasjonalistisk populist - truer med å stille i 2024, suger dette oksygenet ut av den sårt trengte debatten om USAs utenrikspolitiske kursendring. Biden vil forsøke å jobbe frem et skjørt utenrikspolitisk konsensus på de saksområdene han kan, men den underliggende uenigheten vil ligge i landskapet som en udetonert mine: Hva skal egentlig USA være i verden? En liberal hegemon, en tilbaketrukket militær kjempe, eller en bøllete stormakt? Den interne ustabiliteten i USA umuliggjør en Bidens antatte foretrukne strategi der man rett og slett spoler tilbake fire år. Det må sterkere lut til.

USA har dype problemer som må løses, men få tverrpolitiske løsninger i sikte. Innen USA har funnet disse løsningene - og seg selv - har kanskje resten av verden gått videre.

\section{Referanser}

Brands, H. W. (2004). Woodrow Wilson and the irony of fate. Diplomatic History, 28(4), 503-512. https://doi. org/10.1111/j.1467-7709.2004.00427.x

Bush, G. W. (2001a, 20. september). President Bush addresses the nation. The Washington Post. https://www. washingtonpost.com/wp-srv/nation/specials/attacked/transcripts/bushaddress_092001.html

Bush, G. W. (2001b, 16. september). Remarks by the president upon arrival. The White House. https:// georgewbush-whitehouse.archives.gov/news/releases/2001/09/20010916-2.html

Balz, J. \& Clement, J. (2020, 17. september). Poll: Sharp partisan differences now exist on foreign policy, views of American exceptionalism. The Washington Post. https:/www.washingtonpost.com/politics/poll-foreignpolicy-trump-democrats/2020/09/16/8e2d903e-f836-11ea-be57-d00bb9bc632d_story.html

Chollet, D. \& Goldgeier, J. (2008). America between the wars: From 11/9 to 9/11; The misunderstood years between the fall of the Berlin wall and the start of the war on terror. Public Affairs.

Goldberg, J. (2016, april). The Obama doctrine. The Atlantic. https://www.theatlantic.com/magazine/ archive/2016/04/the-obama-doctrine/471525/

Leffler, M. P. (2018, september). America first: Introduction. I M. P. Leffler \& W. Hitchcock (Red.), America first: The past and future of an idea (s. 33-52). Passport. 


\section{Introduksjonsessay til fokusnummer}

MacDonald, P. K. \& Parent, J. M. (2019, 3. desember). Trump didn't shrink U.S. military commitments abroad - he expanded them. Foreign Affairs. https://www.foreignaffairs.com/articles/2019-12-03/trumpdidnt-shrink-us-military-commitments-abroad-he-expanded-them

Monten, J., Busby, J., Kertzer, J. D., Smeltz, D. \& Tama, J. (2020, 3. november). Americans want to engage the world. Foreign Affairs. https:/www.foreignaffairs.com/articles/united-states/2020-11-03/americans-wantengage-world

Restad, H. (2012). The war on terror from Bush to Obama. On power and path dependency. NUPI Working Paper 798. Norwegian Institute of International Affairs.

Restad, H. (2014). American exceptionalism and U.S. foreign policy: An idea that made a nation and remade the world. Routledge.

Restad, H. (2019). Wither the 'city upon a hill'? Donald Trump, America first, and American exceptionalism. Texas National Security Review, 3(1), 63-92. https://nsr.org/2019/12/whither-the-city-upon-a-hill-donaldtrump-america-first-and-american-exceptionalism/

Restad, H. (2020). What makes America great? Donald Trump, national identity, and U.S. foreign policy. Global Affairs, 6(1), 21-36. https://doi.org/10.1080/23340460.2020.1734955

Williamson, V. (2016). What the Tea Party tells us about the Trump presidency. Brookings Institution. https:// www.brookings.edu/blog/fixgov/2016/11/09/tea-party-and-trump-presidency/ 